\title{
Development and Validation of a RP-HPLC Method for Simultaneous Estimation of Antitubercular Drugs in Solid Lipid Nanoparticles
}

\author{
S. KHATAK, MAMTA KHATAK, F. ALI ${ }^{1}$, ASHU RATHI ${ }^{1}$, R. SINGH ${ }^{1}$, G. N. SINGH ${ }^{1}$ AND H. DUREJA*
}

Department of Pharmaceutical Sciences, Maharshi Dayanand University, Rohtak, Haryana-124 001, ${ }^{1}$ Indian Pharmacopoeia Commission (IPC), Sector-23, Raj Nagar, Ghaziabad-201 003, India

Khatak et al.: Simultaneous Estimation of Antitubercular Drugs in SLNs

\begin{abstract}
A new simple, rapid and sensitive reversed-phase high-performance liquid chromatography method was developed and validated as per International Conference on Harmonization guidelines, Q2 (R1), for simultaneous estimation of isoniazid, pyrazinamide and rifampicin in solid lipid nanoparticles. Separation was achieved on a $250 \times 4.6 \mathrm{~mm}, 5 \mu \mathrm{m}, \mathrm{C}-18$ column using a linear gradient flow rate of $1.5 \mathrm{ml} / \mathrm{min}$. Isoniazid, pyrazinamide and rifampicin were identified based on their retention times as compared to standards and confirmed with characteristic spectra on a spectrophotometer at $238 \mathrm{~nm}$ and eluted at $3.787,4.173$ and $11.273 \mathrm{~min}$, respectively, achieved within $20 \mathrm{~min}$. This method was linear, precise with \% RSD values of $0.18 \%$ for isoniazid, $0.15 \%$ for pyrazinamide and $0.47 \%$ for rifampicin, accurate with mean recovery

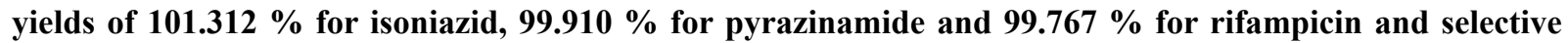
over the concentration range of 10-150 \% for all the three drugs. This method is suitable due to its simplicity and accuracy for routine quality control and stability analysis of antitubercular drugs-loaded solid lipid nanoparticles.
\end{abstract}

Key words: Simultaneous estimation, RP-HPLC, isoniazid, pyrazinamide, rifampicin, solid lipid nanoparticles

Tuberculosis (TB) treatment regimens followed in India under the Revised National Tuberculosis Control Programme (RNTCP) 1997. The initial phase of category-III TB (new cases of smear-negative pulmonary TB with limited parenchymal involvement or less severe forms of extrapulmonary TB, viz., lymph node TB, unilateral pleural effusion, bone (excluding spine), peripheral joint or skin TB) treatment, the combinations of first-line antitubercular drugs (ATDs), isoniazid (INH), pyrazinamide (PYZ) and rifampicin (RIF) are widely used daily per week for at least $2 \mathrm{mo}^{[1]}$. Structures of these first-line three ATDs are depicted in fig. 1A, B and $\mathrm{C}$, respectively. These combination preparations are available in the world market. The International Union against tuberculosis and lung disease and the World Health Organization recognize the potential benefits of using such preparations ${ }^{[2,3]}$.

Spectrophotometric and reversed-phase highperformance liquid chromatography (RP-HPLC) techniques have been reported for individually or the combination of two or more ATDs and other drugs

*Address for correspondence E-mail: harishdureja@gmail.com

November-December 2018 estimation in biological samples and pharmaceutical formulations ${ }^{[4-19]}$. In the previous years, simultaneous estimation of INH, PYZ and RIF in fixed combination of unit doses by high-performance thin layer chromatography ${ }^{[20]}$, multivariate spectrophotometric calibration method ${ }^{[21]}$ and calorimetric analysis ${ }^{[22]}$ have been published. However, many of these methods suffer from limitations such as complex and tedious procedures and are not validated as well.

HPLC is the method of choice for analysis of multicomponent pharmaceutical preparation because of its sensitivity, reproducibility and specificity. The problems associated with optimization of chromatographic conditions such as selection of column type, column temperature, the composition of

This is an open access article distributed under the terms of the Creative Commons Attribution-NonCommercial-ShareAlike 3.0 License, which allows others to remix, tweak, and build upon the work non-commercially, as long as the author is credited and the new creations are licensed under the identical terms

Accepted 10 September 2018

Revised 02 March 2018

Received 13 April 2017

Indian J Pharm Sci 2018;80(6):996-1002 
the mobile phase, selection of the specific wavelength and injection volume. In spite of the fact, this method undoubtedly provides the more sensitive determination than the spectrophotometric methods. It has now become the method of choice for most of the drug and their combinations. Gaitonde and Pathak reported a RP-HPLC method for the simultaneous estimation of INH, PYZ and RIF. They used tetrabutylammonium hydroxide as an ion-pairing agent in the mobile phase which shortens column life ${ }^{[23]}$. Calleri et al. developed an HPLC method having high buffer concentration in the mobile phase of acetonitrile (A) and $50 \mathrm{mM}$ phosphate buffer $\mathrm{pH} 3.5$ (B). The gradient profile was (A:B) $3: 97 \mathrm{v} / \mathrm{v}$ for $5 \mathrm{~min}$, then a linear gradient to $50: 50 \mathrm{v} / \mathrm{v}$ at $30 \mathrm{~min}$ and return to $3: 97 \mathrm{v} / \mathrm{v}$ in $10 \mathrm{~min}$. Chromatography was performed at room temperature using a flow rate of $1 \mathrm{ml} / \mathrm{min}$ and a run time of $40 \mathrm{~min}$. Diode-array detector with three different corresponding maximum of $254 \mathrm{~nm}$ for RIF, $261 \mathrm{~nm}$ for INH and $265 \mathrm{~nm}$ for PYZ were used, this method was time consuming and conditions specific ${ }^{[24]}$. Dhal and Sharma reported RP-HPLC method for simultaneous estimation of pyridoxine hydrochloride, INH, PYZ and RIF. The result showed that the highest values for limits of detection (LOD) were $0.043,0.063,0.036$ and $0.059 \mu \mathrm{g} / \mathrm{ml}$ and limits of quantification (LOQ) were $0.13,0.19,0.11$ and $0.18 \mu \mathrm{g} / \mathrm{ml}$, respectively. So, this method is not sensitive to detect the lowest concentration of combined ATDs ${ }^{[25]}$. The Indian Pharmacopoeia 2014 and United States Pharmacopeia 2016 published HPLC method for simultaneous determination of INH, PYZ and RIF in the tablet and capsule dosage forms ${ }^{[26,27]}$.

The aim of this study was to develop and validate an accurate and sensitive RP-HPLC method for simultaneous estimation of INH, PYZ and RIF in solid lipid nanoparticles (SLNs). The validation results obtained showed that this method was simple, accurate, precise and suitable for the determination of ATDs in SLNs.

\section{MATERIALS AND METHODS}

The working standards employed for INH, PYZ and RIF were obtained from Indian Pharmacopoeia Commission (IPC) Ghaziabad, Uttar Pradesh, India. The Poloxamer 118 (Pluronic F-68) was purchased from HiMedia Laboratory Pvt. Ltd., India. Sodium taurocholate was purchased from LOBA Chemie, India. Stearic acid (octadecanoic acid), mannitol was purchased from Qualigens Fine Chemicals (Division of GSK Pharmaceutical Ltd.). Ortho-phosphoric acid, sodium hydroxide, methanol and acetonitrile of analytical grade were purchased from Thermo Fisher Scientific India Pvt. Ltd. Water was deionized by passing through a Milli-Q ${ }^{\mathrm{TM}}$ Integral-3 water purification system (M-Millipore, Fisher Scientific India Pvt. Ltd.).

Chromatographic experiments were performed using a HPLC instrument (Agilent Technologies 1260 Infinity with EZ Chrome Elite software) equipped with autosampler, ultra-violet/photodiode-array detector (PDA) and stainless steel C-18 column $\left(\right.$ Nucleodur $\left.^{\circledR}\right)$ packed with octadecylsilane bonded to porous silica $(5 \mu \mathrm{m})$, $250 \times 4.6 \mathrm{~mm}$ (Macherey-Nagel $\mathrm{GmbH}$ and Co, Düren, Germany) and the column temperature was maintained at $30^{\circ}$.

\section{Chromatographic conditions:}

Chromatographic analysis were performed in a linear gradient programme using mobile phase A and mobile phase B with the flow rate of $1.5 \mathrm{ml} / \mathrm{min}$ (Table 1). Chromatographic system set the spectrophotometer at $238 \mathrm{~nm}$ and the column temperature was maintained at $30^{\circ}$. The samples were diluted with orthophosphoric acid (OPA) buffer solution $\mathrm{pH} 6.8 \pm 0.02$ and $20 \mu \mathrm{l}$ was injected into the column.

\section{Preparation of the solutions:}

Buffer solution was prepared by diluting $1 \mathrm{ml}$ of OPA in $1000 \mathrm{ml}$ of water and adjusts the $\mathrm{pH} 6.8 \pm 0.02$ with dilute solution of sodium hydroxide. This buffer solution was equivalent to $17.85 \mathrm{mmol}$ OPA buffer solution. Mobile phase A used was a mixture of 96 volumes of buffer and 4 volumes of acetonitrile. Mobile phase B used was a mixture of 45 volumes of buffer and 55 volumes of acetonitrile.

\section{Preparation of stock and standard solution:}

Stock solution was prepared using $0.04 \% \mathrm{w} / \mathrm{v}$ of INH, $0.2 \% \mathrm{w} / \mathrm{v}$ of PYZ and $0.08 \% \mathrm{w} / \mathrm{v}$ of RIF in methanol. The prepared stock solution was stored at $4^{\circ}$ until before use. $5 \mathrm{ml}$ of stock solution was transferred to a volumetric flask and diluted up to $25 \mathrm{ml}$ with buffer. The prepared final concentration of INH, PYZ and RIF were 80,400 and $160 \mu \mathrm{g} / \mathrm{ml}$, respectively.

\section{Calibration solutions:}

Appropriate dilutions of the stock solution were prepared with buffer in $25-\mathrm{ml}$ volumetric flasks. The diluted quality control samples (QCS) of 10, 20, 30, 


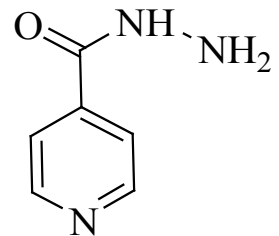

A

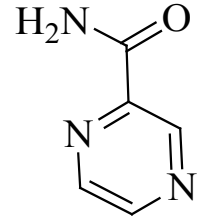

B

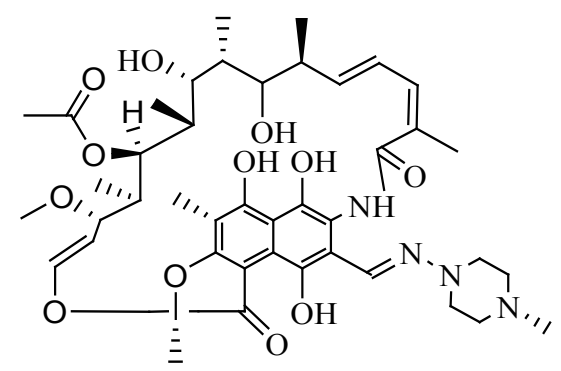

C

Fig. 1: Chemical structures

(A) INH; (B) PYZ and (C) RIF

\section{TABLE 1: THE CONDITIONS OF LINEAR GRADIENT PROGRAMME}

\begin{tabular}{lccc}
\hline $\begin{array}{l}\text { Time } \\
(\mathrm{min})\end{array}$ & $\begin{array}{c}\text { Flow rate } \\
(\mathrm{ml} / \mathrm{min})\end{array}$ & $\begin{array}{c}\text { Mobile phase A } \\
(\% \mathrm{v} / \mathrm{v})\end{array}$ & $\begin{array}{c}\text { Mobile phase B } \\
(\% \mathrm{v} / \mathrm{v})\end{array}$ \\
\hline 0 & 1.5 & 100 & 0 \\
10 & 1.5 & 100 & 0 \\
11 & 1.5 & 0 & 100 \\
15 & 1.5 & 0 & 100 \\
16 & 1.5 & 100 & 0 \\
20 & 1.5 & 100 & 0 \\
\hline
\end{tabular}

$40,50,60,70,80,90,100,110,120,130,140$ and $150 \%$ were prepared and analysed for linearity.

\section{Method validation:}

Validation of the RP-HPLC method was performed as per the International Conference on Harmonization guideline, Q2 (R1) specifications after the establishment of chromatographic and the experimental conditions ${ }^{[28]}$.

\section{System suitability:}

To ensure the validity of the analytical procedure, a system suitability test (SST) was established. Percent relative standard deviation (\% RSD) of the area, RSD of retention time (RT), USP tailing factor, theoretical plates, and resolution were selected for SST. These parameters were analysed by injecting the standard solution six times. The system suitability results are summarized in Table 2 and could be observed as the parameters analysed were in accordance with acceptance criteria.

\section{Specificity:}

Specificity of the method was established to ensure that the components of the SLNs dispersion such as lipid(s) and surfactant(s), does not interfere in the quantification of the drugs ${ }^{[29]}$. The specificity of the method was evaluated by comparing the chromatograms of ATDs extracted from SLNs and of blank nanoparticles to determine the peak purity.

November-December 2018

Indian Journal of Pharmaceutical Sciences

\section{Linearity:}

For linearity, stock solutions of INH, PYZ and RIF at 15 concentrations between 10 to $150 \%$ were injected in triplicate. Calibration curves of standard $\mathrm{INH}$, PYZ and RIF were generated by plotting the analyte peak area versus \% drug concentration. Linearity is confirmed if the \% RSD values of the slope and the intercept are $<1 \%$.

\section{Precision:}

The system precision of the method was determined by performing intra-day and inter-day analysis by triplicate injections of the QCS. The \% RSD $(\% \mathrm{RSD}=\mathrm{SD} /$ mean $\times 100)$ and $\%$ accuracy $(\%$ accuracy $=$ mean area of test/mean area of standard $\times 100$ ) were calculated by comparing the theoretical and measured concentration for each case (Table 3). According to the ICH guideline, coefficients of variation for the precision shall not exceed $5 \%$.

\section{Accuracy:}

To determine the accuracy of the proposed method, recovery studies were conducted. The extraction process of the method was quantified by comparing three separately extracted sample preparation (SLNs containing ATDs and excipients) against a standard solution. The acceptance criterion for the extraction study was the mean recovery of the extracted ATDs from SLNs relative to the standard solution shown in Table 4.

\section{LOD and lower LOQ:}

LOD was the lowest concentration of the analyte in a sample that could be detected under the stated experimental condition. LOQ is the lowest concentration of the active ingredients in a sample that could be determined with acceptable precision and accuracy. According to the $\mathrm{ICH}$ recommendation, the approach based on the standard deviation (SD) of 
TABLE 2: SYSTEM SUITABILITY RESULTS

\begin{tabular}{lcccc}
\hline Parameters & Limits & \multicolumn{3}{c}{ ATDs } \\
\cline { 3 - 5 } \% RSD of the area & Less than 2 & INH & PYZ & 0.05 \\
RSD of retention time & Less than 1.0 & 0.05 & 0.08 & 0.06 \\
USP tailing factor & Less than 2 & $1.26 \pm 0.069$ & $1.25 \pm 0.147$ & 0.02 \\
Theoretical plates & More than 2000 & $27647 \pm 226.57$ & $33317 \pm 267.23$ & $1.27 \pm 0.070$ \\
Resolution & More than 2 & - & $3.94 \pm 0.01$ & $98821 \pm 268.59$ \\
\hline
\end{tabular}

System suitability was checked by injecting the working solution six times

TABLE 3: INTRA-DAY AND INTER-DAY PRECISION AND ACCURACY OF INH, PYZ AND RIF

\begin{tabular}{|c|c|c|c|c|c|c|c|c|c|c|c|c|}
\hline \multirow{3}{*}{ QCS } & \multirow{2}{*}{\multicolumn{3}{|c|}{ Amount $(\mu \mathrm{g} / \mathrm{ml})$}} & \multicolumn{9}{|c|}{ Standard (Intra-days) } \\
\hline & & & & \multicolumn{3}{|c|}{ Found $(\mu \mathrm{g} / \mathrm{ml})$} & \multicolumn{3}{|c|}{ Accuracy (\%) } & \multicolumn{3}{|c|}{ Precision (\% RSD) } \\
\hline & INH & PYZ & RIF & INH & PYZ & RIF & INH & PYZ & RIF & INH & PYZ & RIF \\
\hline $10 \%$ & 8 & 40 & 16 & 7.90 & 39.60 & 15.90 & 98.72 & 99.00 & 99.35 & 0.04 & 0.05 & 0.47 \\
\hline $50 \%$ & 40 & 200 & 80 & 39.64 & 198.19 & 79.29 & 99.09 & 99.09 & 99.11 & 0.18 & 0.15 & 0.16 \\
\hline $100 \%$ & 80 & 400 & 160 & 79.36 & 396.56 & 158.27 & 99.20 & 99.14 & 98.92 & 0.03 & 0.07 & 0.06 \\
\hline \multirow[t]{2}{*}{$150 \%$} & 120 & 600 & 240 & 119.17 & 595.15 & 237.53 & 99.31 & 99.19 & 98.97 & 0.05 & 0.02 & 0.08 \\
\hline & & & & \multicolumn{9}{|c|}{ Standard (Inter-days) } \\
\hline $10 \%$ & 8 & 40 & 16 & 7.85 & 40.11 & 15.73 & 98.09 & 100.28 & 98.30 & 0.14 & 0.01 & 0.32 \\
\hline $50 \%$ & 40 & 200 & 80 & 39.84 & 200.36 & 79.73 & 99.60 & 100.18 & 99.67 & 0.03 & 0.05 & 0.06 \\
\hline $100 \%$ & 80 & 400 & 160 & 79.98 & 400.91 & 159.74 & 99.98 & 100.23 & 99.84 & 0.08 & 0.05 & 0.07 \\
\hline $150 \%$ & 120 & 600 & 240 & 119.98 & 601.05 & 240.64 & 99.98 & 100.18 & 100.27 & 0.01 & 0.01 & 0.01 \\
\hline
\end{tabular}

TABLE 4: RECOVERY ANALYSIS OF ATDs-LOADED SLNs

\begin{tabular}{lccccc}
\hline \multirow{2}{*}{ ATDs } & \multicolumn{3}{c}{ Assay $^{\text {a }}$} & \multicolumn{3}{c}{ Recovery $^{\text {a }}$} \\
\cline { 2 - 6 } & Found $(\mu \mathrm{g} / \mathrm{ml})$ & \% RSD & Mean recovery $(\%)$ & \pm SD & $\%$ RSD \\
\hline INH & 0.3424 & 0.53 & 101.312 & 939.74 & 6.11 \\
PYZ & 1.4623 & 0.06 & 99.910 & 188.80 & 0.12 \\
RIF & 1.1194 & 0.39 & 99.767 & 7.07 & 0.07 \\
\hline
\end{tabular}

aMean of two extractions (each analyzed in duplicate)

the response and slope $(\mathrm{m})$ was used for determining the detection and quantitation limits. LOD can be calculated according to the formula, $\mathrm{LOD}=3.3$ $(\mathrm{SD} / \mathrm{m})$ and $\mathrm{LOQ}$ according to the formula, $\mathrm{LOQ}=10$ $(\mathrm{SD} / \mathrm{m})^{[30]}$.

\section{Determination of ATDs encapsulation efficiency (EE) in SLNs:}

SLNs were prepared using a modified microemulsion technique, freeze-dried and stored at $4^{\circ[31]}$. The mean particle size and the polydispersity index (PDI) were determined using dynamic light scattering (Malvern Instruments Ltd. Zetasizer Ver. 7.11), at room temperature. To determine the amount of ATDs in SLNs, $5 \mathrm{mg}$ of lyophilized SLNs were transferred into a 5 -ml volumetric flask and $3 \mathrm{ml}$ of ethanol was added. This mixture was heated to $50^{\circ}$ with sonication and final volume was made up to $5 \mathrm{ml}$ of ethanol ${ }^{[32,33]}$. The above solution $(1 \mathrm{ml})$ was placed in a $50 \mathrm{ml}$ volumetric flask and diluted with buffer. The sample was ultrasonicated for $10 \mathrm{~min}$ and filtered with nylon syringe filter $(0.22 \mu \mathrm{m})$. Further $1 \mathrm{ml}$ of the filtrate was diluted up to $10 \mathrm{ml}$ with buffer. The sample was analysed by using the designed chromatographic conditions as discussed earlier. Subsequently, the EE was calculated with the help of the reported Eqn. ${ }^{[34]}, \% \mathrm{EE}=($ total drug - free drug $) /($ total drug $) \times 100$. Where, total drug corresponds to the amount of ATDs initially added to the SLNs dispersion and free drug is the amount of the drug not incorporated into the lipid nanoparticle, quantified by RP-HPLC method. The $\%$ EE was quantified by RP-HPLC method and the value of $\% \mathrm{EE}$ was expressed as mean and $\mathrm{SD}^{[34]}$.

\section{RESULT AND DISCUSSION}

In order to optimize good separation between all the three ATDs drugs at different buffer $\mathrm{pH}$ and organic solvents like acetonitrile and water tested binary and tertiary eluents. Therefore, best chromatographic conditions concluded with different ratio of $17.85 \mathrm{mmol}$ OPA buffer $(\mathrm{pH}$ 6.8) and acetonitrile, flow rate of $1.5 \mathrm{ml} / \mathrm{min}$ and detected at $238 \mathrm{~nm}$. The analytical profile obtained by injection of a standard working solution was reported in fig. 2. The analytical profiles obtained 
by injection of extracted spiked SLNs without active pharmaceutical ingredients and of extracted spiked ATDs-loaded SLNs were reported in fig. 3. The SST parameters such as RT, USP tailing, theoretical plates and resolution for optimizing standard chromatogram are tabulated in Table 2.

The SST is an integrated part of the analytical method and it ascertains the suitability and effectiveness of the operating system. The results were within the limit and are presented in Table 2 and system suitability chromatogram in fig. 2. The USP tailing factor for the analytes peaks were less than 2.0 , the \% RSD of the peak areas responses less than $2 \%$ and the migration times within seconds.

Specificity is the ability of the method to measure the analyte response in the presence of its potential impurities and degradation products ${ }^{[35]}$. The representative chromatograms of INH, PYZ and RIF were identified with the RT as compared with the standard at 3.887, 4.200 and $11.327 \mathrm{~min}$, respectively. The specificity studies revealed the absence of any other excipients interference, since none of the peaks appeared at the same RT, as shown in fig. 3. The specificity was justified from complete separation of drugs from SLNs and indicated that there was no interference in the quantitative determination of ATDs from SLNs components.

Linear responses were observed in the range of 8-120, 40-600 and $16-240 \mu \mathrm{g} / \mathrm{ml}$ for INH, PYZ and RIF,

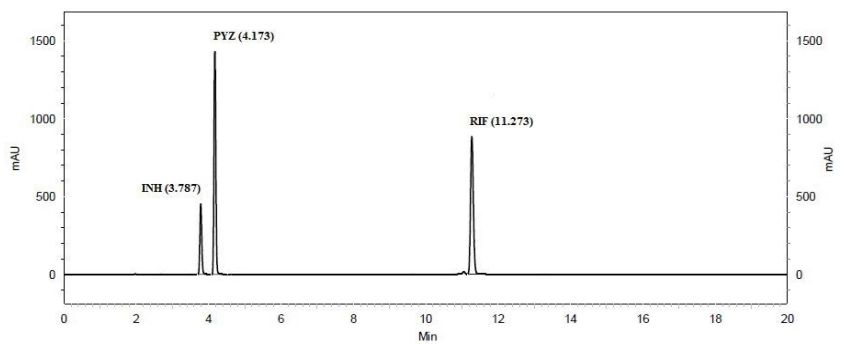

Fig. 2: System suitability chromatogram of INH, PYZ and RIF

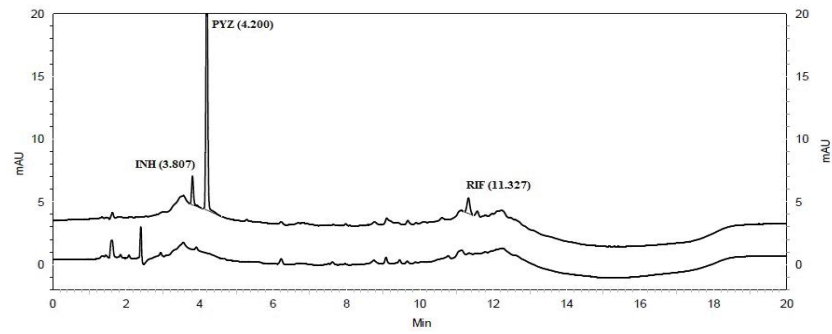

Fig. 3: Analytical profile of extracted spiked SLNs without ATDs and with ATDs

The analytical profile obtained by injection of extracted spiked SLNs without APIs and with ATDs-loaded SLNs respectively. The linear regression analysis obtained by plotting the peak areas of the three analytes versus percent concentration. The result showed excellent correlation coefficients $\left(R^{2} \geq 0.999\right)$ and the linearity data was reported in Table 5 .

Intra-day and inter-day precision, as well as accuracy data obtained from the experiments, are given in Table 3 . The $\%$ RSD values for intra-day and inter-day precision study were $<0.18 \%$ for $\mathrm{INH},<0.15 \%$ for $\mathrm{PYZ}$ and $<0.47 \%$ for RIF confirming that the method was adequately precise. Accuracy values were $>98.09$ and $<98.98 \%$ for INH, $>99.00$ and $<100.28 \%$ for PYZ and $>98.30$ and $<100.27 \%$ for RIF indicated the level of accuracy of the method.

The mean recovery data obtained were within $2 \%$. The mean recovery yields were 101.312, 99.910 and $99.767 \%$ for INH, PYZ and RIF, respectively. The recovery data is reported in Table 4 . Since the results obtained were within the acceptable $\pm 3 \%$ range, the method was deemed to be accurate. Estimation of LOD and LOQ considered the acceptable SD of the response and the slope of the standard curve. The LOD and LOQ was calculated as 0.0042 and 0.0127 for INH, 0.0023 and 0.0070 for PYZ and 0.0475 and $0.1439 \mu \mathrm{g} / \mathrm{ml}$ for RIF, respectively (Table 6).

The SLNs containing ATDs were successfully obtained by microemulsion technique and proposed analytical method was applied to evaluate the EE of ATDs in SLNs. As shown in the specificity test, no alterations or unusual peaks were observed in the chromatograms during the drug quantitation. The mean recovery yields were 101.312, 99.910 and $99.767 \%$ for INH, PYZ and RIF, respectively. The results demonstrated that the method used was efficient in associating the drugs with SLNs. The average diameter of the solid nanoparticles was $374.1 \pm 3 \mathrm{~nm}$ and PDI $(0.436 \pm 0.005)$ indicating mono-modal size distribution. Therefore, the proposed RP-HPLC method represented an alternative method for the simultaneous estimation of INH, PYZ and RIF in SLNs. The method fulfilled all requirements and considered as reliable, feasible and could be applied for the determination of assay, EE, in vitro drug release and stability of ATDs-loaded SLNs.

The RP-HPLC method developed was found to be a convenient and cost-effective method for the simultaneous estimation of INH, PYZ and RIF in SLNs. This method was validated according to the ICH guidelines Q2 (R1) and was found to be a reliable 
TABLE 5: LINEAR REGRESSION ANALYSIS

\begin{tabular}{lcccc}
\hline ATDs & Linearity range $(\mu \mathrm{g} / \mathrm{ml})$ & Slope $^{\mathrm{a}} \pm \%$ RSD & Intercept $^{\mathrm{a}} \pm \%$ RSD & Correlation coefficient $\left(\mathrm{R}^{2}\right)$ \\
\hline $\mathrm{INH}$ & $8-120$ & $34490.67 \pm 0.003967$ & $-32035.00 \pm 0.234533$ & 0.9980 \\
PYZ & $40-600$ & $111140.7 \pm 0.000387$ & $-5078.07 \pm 0.052567$ & 0.9980 \\
RIF & $16-240$ & $100030.3 \pm 0.001377$ & $-101244 \pm 0.080767$ & 0.9981 \\
\hline
\end{tabular}

Mean $(n=3)$

TABLE 6: RESULTS OF LOD AND LOQ

\begin{tabular}{lccccc}
\hline ATDs & SD & Slope & \% RSD & LOD & LOQ \\
\hline INH & 43.715 & 34491 & 0.12 & 0.0042 & 0.0127 \\
PYZ & 77.797 & 111141 & 0.06 & 0.0023 & 0.0070 \\
RIF & 1439.66 & 100030 & 1.34 & 0.0475 & 0.1439 \\
\hline
\end{tabular}

and feasible method, which included specificity, linearity, precision, accuracy, LOD and LOQ. The chromatographic run time was $20 \mathrm{~min}$, which allowed numerous samples to be analysed in a short period, as well as reduced solvent costs and damage to the environment. Hence it was concluded that the validation parameters showed the method to be excellent for the routine quality control analysis of INH, PYZ and RIF ATDs-loaded SLNs.

\section{Conflict of interest:}

The authors confirm that this article content has no conflict of interest.

\section{Acknowledgements:}

One of the author's Sunil Khatak is grateful to IPC, Ghaziabad, UP, India, for providing necessary instrumental facilities and gift samples of ATDs.

\section{REFERENCES}

1. Khatak S, Dureja H. Recent advances in nanotechnology based tubercular chemotherapy. Int J Pharm Sci Nanotech 2015;8(4):2919-34.

2. Global tubercular report 2015, 20 $0^{\text {th }}$ ed. World Health Organization. 2015; p. 1-115. Available from: www.who.int/ tb/publications/global_report/gtbr15_main_text.pdf.

3. The union health solutions for the poor. International union against tuberculosis and lung disease, activity report 2012.68, boulevard Saint-Michel-75006, Paris-France. 2012; p. 1-73. Available from: www.theunion.org/what-we-do/publications/ official/english/Rapport_2012-print5LR6.pdf.

4. Benetton SA, Kedor-Hackmann ER, Santoro MI, Borges VM. Visible spectrophotometric and first-derivative UV spectrophotometric determination of rifampicin and isoniazid in pharmaceutical preparations. Talanta 1998;47(3):639-43.

5. Swamy N, Prashanth KN, Basavaiah K. Redox-reaction based spectrophotometric assay of isoniazid in pharmaceuticals. ISRN Anal Chem 2014;2014:717019.

6. Kamel MS. Spectrophotometric determination of isoniazid in pure form and pharmaceutical preparation. World $\mathrm{J}$ Chem 2008;3(1):11-6.
7. Tsai IL, Liu HY, Kuo PH, Wang JY, Shen LJ, Kuo CH. Quantitative determination of isoniazid in biological samples by cation-selective exhaustive injection-sweepingmicellar electrokinetic chromatography. Anal Bioanal Chem 2011;401(7):2205-14.

8. Huang J, Zhang C, Zhang Z. Flow-injection chemiluminescence determination of isoniazid with electro-generated hypochlorite. Fresenius J Anal Chem 1999;363:126-28.

9. Zheng $\mathrm{X}$, Zhang Z. Flow-injection chemiluminescence determination of isoniazid using on-line electrogenerated $\mathrm{BrO}$ as an oxidant. Analyst 1999;124:763-66.

10. Lapa RAS, Lima JLFC, Santos JLM. Fluorimetric determination of isoniazid by oxidation with cerium (IV) in a multi-commutated flow system. Anal Chim Acta 2000;419:17-23.

11. Smith PJ, van Dyk J, Fredericks A. Determination of rifampicin, isoniazid and pyrazinamide by high-performance liquid chromatography after their simultaneous extraction from plasma. Int J Tuberc Lung Dis. 1999;3(11 Suppl 3):S325-28.

12. Allanson AL, Cotton MM, Tettey LNA, Boyter AC. Determination of rifampicin in human plasma and blood spots by high-performance liquid chromatography with UV detection: A potential method for therapeutic drug monitoring. J Pharm Biomed Anal 2007;44(4):963-69.

13. Li B, He Y, Lv J, Zhang Z. Simultaneous determination of rifampicin and isoniazid by continuous-flow chemiluminescence with artificial neural network calibration. Anal Bioanal Chem 2005;383:817-24.

14. Padmarajaiah N, Kallanchira S, Ramanathapura V, Hemmige Y. A novel method for the spectrophotometric determination of isoniazid and ritodrine hydrochloride. Turk J Chem 2002;26:743-50.

15. Khuhawar MY, Rind FM. High performance liquid chromatographic determination of isoniazid, pyrazinamide and rifampicin in pharmaceutical preparations. Pak J Pharm Sci 1998;11(2):49-54.

16. Prasad ST, Rao KNV, Chaithanya Y, Raghavendha P, Surendra M, Banji D. Method development and validation of RP-HPLC method for simultaneous estimation of rifampicin, isoniazid and pyridoxine hydrochloride in bulk pharmaceutical dosage form. Int J Pharm Res Develop 2012;4(8):153-62.

17. Rote AR, Sharma AK. Simultaneous spectrophotometric determination of rifampicin, isoniazid and pyrazinamide by first-derivative UV spectrophotometry in the combined pharmaceutical dosage form. Indian $\mathrm{J}$ Pharm Sci 1997;59(3):119-23.

18. Khuhawar MY, Rind FMA, Rajper AD. High-performance 
liquid chromatographic determination of isoniazid, pyrazinamide, and indomethacin in pharmaceutical preparations. Acta Chromatogr 2005;15:269-75.

19. Hammam E, Beltagi AM, Ghoneim MM. Voltammetric assay of rifampicin and isoniazid drugs, separately and combined in bulk, pharmaceutical formulations and human serum at a carbon paste electrode. Microchem J 2004;77(1):53-62.

20. Argekar AP, Kunjir SS, Purandare KS. Simultaneous determination of rifampicin, isoniazid and pyrazinamide by high-performance thin layer chromatography. J Pharm Biomed Anal 1996;14(11):1645-50.

21. Goicoechea HC, Olivieri AC. Simultaneous determination of rifampicin, isoniazid and pyrazinamide in tablet preparations by multivariate spectrophotometric calibration. J Pharm Biomed Anal 1999;20:681-86.

22. Ellard GA. The colourimetric analysis of antitubercular fixeddose combination tablets and capsules. Int J Tuberc Lung Dis 1999;3(11 Suppl 3):S343-46.

23. Gaitonde CD, Pathak PV. Rapid and sensitive estimation of isoniazid, pyrazinamide and rifampicin in combined dosage form by reversed-phase liquid chromatography. Drug Dev Ind Pharm 1991;17(9):1201-14.

24. Calleri E, De Lorenzi E, Furlanetto S, Massolini G, Caccialanza G. Validation of a RP-LC method for the simultaneous determination of isoniazid, pyrazinamide and rifampicin in a pharmaceutical formulation. J Pharm Biomed Anal 2002;29:1089-96.

25. Dhal SK, Sharma R. Development and validation of RPHPLC method for simultaneous determination of pyridoxine hydrochloride, isoniazid, pyrazinamide and rifampicin in pharmaceutical formulation. Chem Anal 2009;54(6):1487500 .

26. Indian Pharmacopoeia. 7th ed. The Indian Pharmacopoeia Commission. India: Indian Pharmacopoeia Laboratory, Govt. of India-MHFW; 2014. p. 2668-9.
27. The United States Pharmacopoeia-39, The National Formulary-34. Baltimore, Maryland: United State Pharmacopeial Convention, United Book Press; 2016. p. 5707-8.

28. International Conference on Harmonization (ICH), harmonised tripartite guideline for validation of analytical procedures, text and methodology Q2 (R1). 2005: Part 1; p. 1-13. Available from: www.ich.org/fileadmin/Public_Web_ Site/ICH_Products/Guidelines/Quality/Q2_R1/Step4/Q2_ R1_Guideline.pdf.

29. Ribani M, Bottoli CBG, Collins CH, Jardim ICSF, Melo LFC. Validação em métodos cromatográficos e eletroforéticos. Quim Nova 2004;27(5):771-80.

30. Sehrawat R, Khatak M, Kumar A, Khatak S. Development and validation of RP-HPLC method for simultaneous estimation of phenylephrine hydrochloride and chlorpheniramine maleate in pharmaceutical dosage form. Int Pharm Sci 2013;3(2):91-5.

31. Parhi R, Suresh P. Production of solid lipid nanoparticlesdrug loading and release mechanism. J Chem Pharm Res 2010;2(1):211-27.

32. Pandey R, Sharma S, Khuller GK. Oral solid lipid nanoparticlebased antitubercular chemotherapy. Tuberculosis 2005;85(56):415-20.

33. Pandey R, Khuller GK. Solid lipid particle-based inhalable sustained drug delivery system against experimental tuberculosis. Tuberculosis 2005;85(4):227-34.

34. Antunes JOR, Antônio E, Mainardes RM, Khalil NM. Development and validation of HPLC-PDA method for quantitative determination of diphenyl diselenide in poly(lactide) nanoparticles. Curr Pharm Anal 2016;12:121-8.

35. Garciia A, Rupérez FJ, Mariin A, Maza A, Barbas C. Poly (ethylene glycol) column for the determination of acetaminophen. chlorpheniramine and phenylephrine in the pharmaceutical preparation. J Chromatogr B $2003 ; 785: 237-43$. 